\title{
Identification of a novel MYOC variant in a Hispanic family with early-onset primary open-angle glaucoma with elevated intraocular pressure
}

\author{
June Criscione, ${ }^{1}$ Weizhen Ji, ${ }^{1}$ Lauren Jeffries, ${ }^{1}$ James M. McGrath, ${ }^{2}$ \\ Scott Soloway, ${ }^{3}$ Lajos Pusztai, ${ }^{4}$ and Saquib Lakhani ${ }^{1}$ \\ ${ }^{1}$ Pediatric Genomics Discovery Program, Department of Pediatrics, ${ }^{2}$ Department of Genetics, ${ }^{3}$ Department of \\ Ophthalmology, ${ }^{4}$ Yale Cancer Center Genetics, Genomics, and Epigenetics Program, Yale University School \\ of Medicine, New Haven, Connecticut 06520, USA
}

\begin{abstract}
Primary open-angle glaucoma (POAG) is the leading cause of irreversible blindness worldwide. Most cases are multifactorial in etiology, but some are associated with variants in the myocilin gene, MYOC. Here, we report the identification of a novel MYOC variant, c.1153G >A, in a 24-yr-old female patient with a personal and family history of juvenile/early-onset POAG. Further genetic testing within her family demonstrated that this variant segregates with the POAG phenotype in an autosomal dominant pattern. Identification of this MYOC variant in multiple affected relatives provides evidence for its pathogenicity, supporting previous findings linking MYOC mutations, in particular in the third exon's olfactomedin domain, to juvenile-onset POAG. This case also emphasizes the potential value of genetic testing in families with histories of eye disorders.
\end{abstract}

Corresponding author: saquib.lakhani@yale.edu

(C) 2019 Criscione et al. This article is distributed under the terms of the Creative Commons Attribution-NonCommercial License, which permits reuse and redistribution, except for commercial purposes, provided that the original author and source are credited.

Ontology term: primary open angle glaucoma

Published by Cold Spring Harbor Laboratory Press

doi:10.1101/mcs.a004374

\section{CASE PRESENTATION}

With a global prevalence of $~ 3 \%$ and cases projected to reach 53-65.5 million by 2020, primary open-angle glaucoma (POAG) is the leading cause of irreversible blindness worldwide (Tham et al. 2014; Weinreb et al. 2014; Kapetanakis et al. 2016; Weinreb et al. 2016).

Most cases of POAG are multifactorial in etiology. However, monogenic autosomal dominant inheritance patterns may account for up to $10 \%$ of glaucoma cases, including certain presentations of POAG (Kwon et al. 2009). Of particular note, juvenile-onset high-tension POAG with intraocular pressure (IOP) typically $\geq 40 \mathrm{mmHg}$ (normal $<20 \mathrm{mmHg}$ ) has been associated with mutations in the myocilin gene MYOC (NM_000261), which may also account for up to $5 \%$ of adult-onset disease (Stone et al. 1997; Alward et al. 2002; Wang et al. 2019).

Our proband (Fig. 1A, patient IV-2) is a 24-yr-old female who was diagnosed with bilateral POAG at age $9 \mathrm{yr}$. Her condition was medically managed until age $18 \mathrm{yr}$ when IOP rose to 42 $\mathrm{mmHg}$. Increased disc cupping was also noted at this time.

She underwent trabeculectomy procedures at age 18 (oculus sinister) and 20 (oculus dexter) yr. Both procedures were complicated by hypotony maculopathy requiring two revisions. Since then, her glaucoma has been managed without medications. Upon exam at age $24 \mathrm{yr}$, 

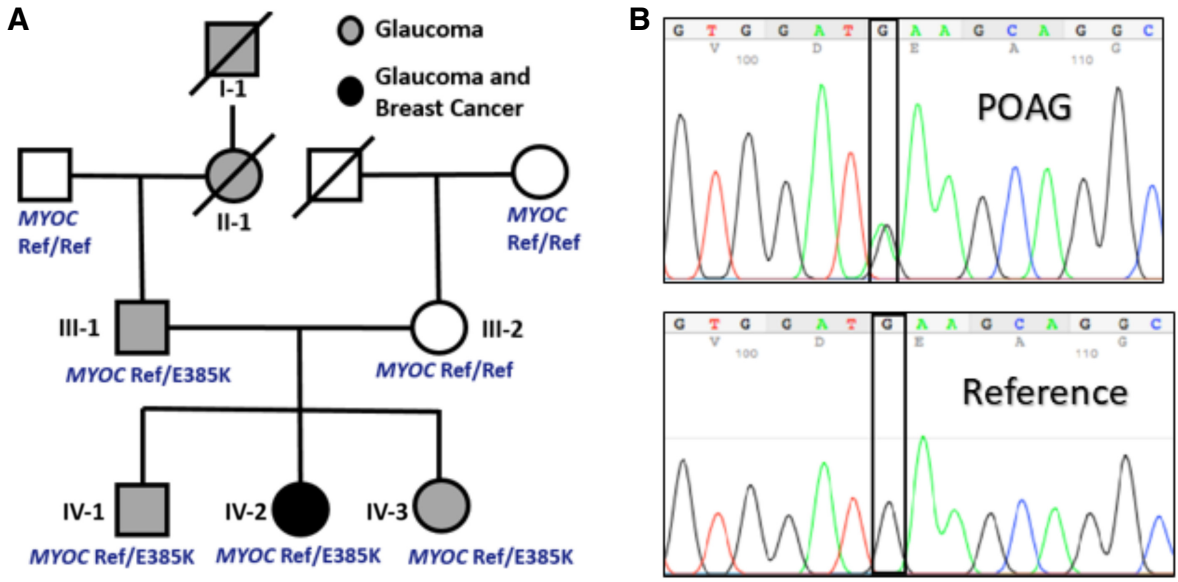

C

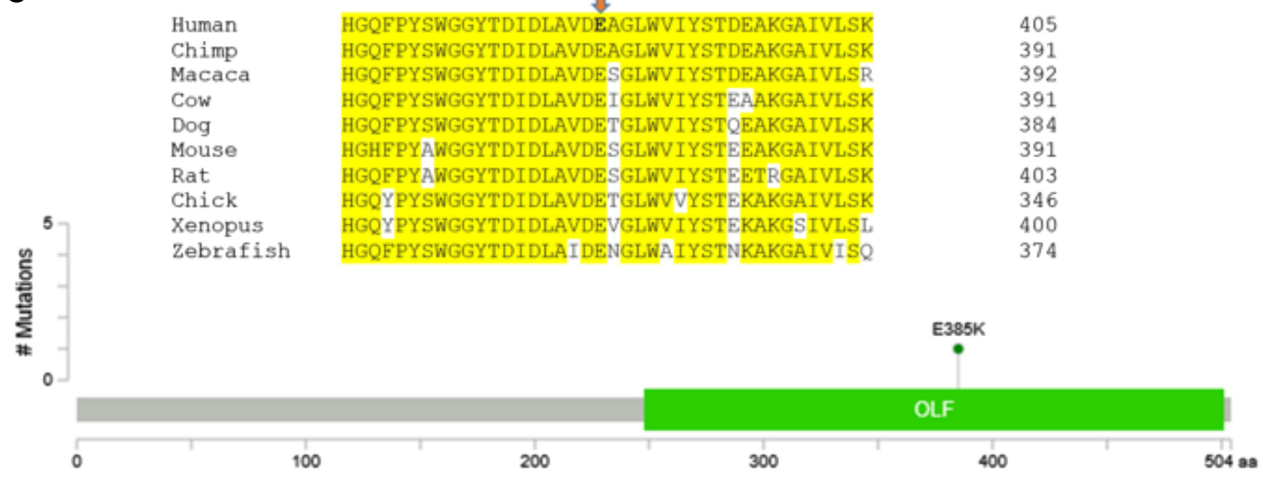

Figure 1. (A) The IV-2 family pedigree. The proband, IV-2, has a four-generation family history of early-onset glaucoma, including her great-grandfather (I-1), her grandmother (II-1), her father (III-1), and her siblings (IV-1 and IV-3). All living relatives with POAG are heterozygous for the p.Glu385Lys MYOC mutation, whereas unaffected relatives are homozygous wild-type. IV-2 does not have a family history of breast cancer or any known genetic risk factors for breast cancer. (B) Sanger sequencing. The c.1153G>A, p.Glu385Lys variant found in the proband and affected family members with POAG is demonstrated in comparison to the $\mathrm{G} / \mathrm{G}$ reference sequence. (C) Conservation and location of the c.1153G>A, p.Glu385Lys variant. The p.Glu385Lys variant, which exchanges a highly conserved negatively charged glutamic acid for a positively charged lysine residue, occurs in the olfactomedin exon 3 of MYOC, the same region as a majority of previously identified POAGassociated MYOC mutations.

she had 20/25 vision in both eyes, corrected with glasses. Her IOP is currently stable at ح-13 $\mathrm{mmHg}$ in both eyes.

The proband is one of three siblings born to nonconsanguineous Hispanic parents. Her brother was diagnosed with bilateral juvenile-onset POAG at age $19 \mathrm{yr}$ and her sister received the same diagnosis at age $20 \mathrm{yr}$ (patients IV-1 and IV-3). Her brother's condition is currently managed with medical therapy, but her sister has undergone a trabeculectomy. Her father (patient III-1) was diagnosed with juvenile-onset POAG in his 20s and received a trabeculectomy at age 26 following initial medical management. He also has adult-onset diabetes mellitus, but is otherwise healthy. Her mother (patient III-2) has adult-onset glaucoma.

The proband's paternal grandmother (patient II-1) had early-onset glaucoma and adultonset diabetes. She began medical therapy in her 30s and later underwent trabeculectomy and laser surgery procedures. Her paternal great-grandfather (patient I-1) also had early- 
onset glaucoma, which led to significant visual impairment by his mid-30s and eventually rendered him blind.

\section{TECHNICAL ANALYSES}

The proband was referred for genetic testing following a diagnosis of stage lla ductal adenocarcinoma of the breast at age $23 \mathrm{yr}$. Prior to exome sequencing, a commercially available panel evaluating genes associated with hereditary cancer was sent and found to be negative.

Subsequent germline exome sequencing of the proband and her parents, which was completed under a research protocol at the Yale Center for Genome Analysis (Table 1), also failed to identify any known genetic risk factors for breast cancer. However, given that the proband and her father both have juvenile/early-onset POAG, we examined their sequences for rare heterozygous variants in common that were also not present in her mother's sequence (Table 2). Among these, we identified a novel variant in MYOC, NM_000261.2: c.1153G >A, p.Glu385Lys, located at a highly conserved residue within the olfactomedin-homology domain in exon 3 (Table 3). Multiple in silico algorithms, including CADD, SIFT and PolyPhen, predict this to be a deleterious variant. Furthermore, this variant is extremely rare, given that it is absent from the gnomAD database.

Subsequently, we sequenced this locus in the proband and all available first- or seconddegree family members using Sanger sequencing. All individuals with juvenile/early-onset POAG — the proband, her father, and her two siblings — were determined to be heterozygous

\begin{tabular}{|c|c|c|c|}
\hline & Proband & Father & Mother \\
\hline Read length & 99 & 99 & 99 \\
\hline Num reads (M) & 45.8 & 49.3 & 57.9 \\
\hline Num bases $(G)$ & 4.5 & 4.9 & 5.7 \\
\hline Mean coverage & 41.6 & 43.8 & 50.7 \\
\hline Median coverage & 39 & 40 & 48 \\
\hline PCR duplicates & $20.38 \%$ & $22.49 \%$ & $24.71 \%$ \\
\hline Multiply mapped & $6.25 \%$ & $6.57 \%$ & $6.36 \%$ \\
\hline Unmapped & $0.05 \%$ & $0.06 \%$ & $0.04 \%$ \\
\hline Reads on-target & $53.63 \%$ & $51.56 \%$ & $51.55 \%$ \\
\hline Bases on-target & $42.65 \%$ & $41.05 \%$ & $41.12 \%$ \\
\hline Mean error rate & $0.24 \%$ & $0.26 \%$ & $0.22 \%$ \\
\hline $1 \times$ target base coverage & $95.1 \%$ & $95.1 \%$ & $95.1 \%$ \\
\hline $2 \times$ target base coverage & $94.9 \%$ & $94.9 \%$ & $94.9 \%$ \\
\hline $4 \times$ target base coverage & $94.7 \%$ & $94.7 \%$ & $94.7 \%$ \\
\hline $8 \times$ target base coverage & $94.1 \%$ & $94.1 \%$ & $94.3 \%$ \\
\hline $10 \times$ target base coverage & $93.5 \%$ & $93.6 \%$ & $94.1 \%$ \\
\hline $15 \times$ target base coverage & $90.4 \%$ & $90.8 \%$ & $92.7 \%$ \\
\hline $20 \times$ target base coverage & $84.7 \%$ & $85.4 \%$ & $89.8 \%$ \\
\hline $30 \times$ target base coverage & $67.9 \%$ & $69.6 \%$ & $78.8 \%$ \\
\hline $40 \times$ target base coverage & $48.7 \%$ & $51.5 \%$ & $63.5 \%$ \\
\hline $50 \times$ target base coverage & $31.7 \%$ & $35.3 \%$ & $47.3 \%$ \\
\hline $100 \times$ target base coverage & $1.8 \%$ & $2.7 \%$ & $4.5 \%$ \\
\hline
\end{tabular}


Table 2. Rare heterozygous variants

\begin{tabular}{|c|c|c|c|c|c|c|c|}
\hline Gene & Chromosome & HGVS cDNA & HGVS protein & Max freq & CADD & SIFT & $\mathrm{PPH}$ \\
\hline WDR63 & $1: 85589887$ & NM_145172:c.2065C>G & p.L689V & 0 & 24.9 & $\mathrm{D}$ & $\mathrm{D}$ \\
\hline GOLPH3L & 1:150667289 & NM_018178:c.26G>A & p.R9H & $1.66 \times 10^{-05}$ & 27.2 & $\mathrm{D}$ & $\mathrm{D}$ \\
\hline MYOC & 1:171605427 & NM_000261.2:c.1153G>A & p.E385K & 0 & 26.2 & D & D \\
\hline $\mathrm{RC} 3 \mathrm{H} 1$ & 1:173915647 & NM_172071:c.2928G>T & p.Q976H & 0 & 26.5 & $\mathrm{D}$ & $\mathrm{D}$ \\
\hline PRKD3 & $2: 37486821$ & NM_005813:c.2050C>T & p.L684F & 0 & 29.6 & $\mathrm{D}$ & $\mathrm{D}$ \\
\hline LRP1B & $2: 141660657$ & NM_018557:c.3598C>A & p.P1200T & 0 & 25.5 & $\mathrm{D}$ & $\mathrm{D}$ \\
\hline NCKIPSD & $3: 48716342$ & NM_016453:c.1760C>T & p.S587F & 0 & 28.3 & $\mathrm{D}$ & $\mathrm{D}$ \\
\hline NIPAL1 & $4: 48032145$ & NM_207330:c.322G>A & p.G108R & 0 & 34 & $\mathrm{D}$ & $\mathrm{D}$ \\
\hline CSF1R & $5: 149433678$ & NM_005211:c.2873A>T & p.D958V & $8.81 \times 10^{-05}$ & 25.6 & $\mathrm{D}$ & $\mathrm{D}$ \\
\hline RPS6KA2 & 6:167275598 & NM_001006932:c.61G>C & p.E210 & 0 & 22.4 & $\mathrm{~T}$ & $\mathrm{D}$ \\
\hline FREM1 & $9: 14845969$ & NM_144966:c.1382T>G & p.L461R & 0 & 26.6 & $\mathrm{D}$ & $\mathrm{D}$ \\
\hline GCNT1 & $9: 79118564$ & NM_001490:c.1267T>A & p.L423M & 0 & 22.9 & $\mathrm{D}$ & $P$ \\
\hline FANCF & $11: 22646752$ & NM_022725:c.604delC & p.L202X & 0 & . & . & . \\
\hline MUC15 & $11: 26587076$ & NM_001135092:c.410dupC & p.P137fs & 0 & . & . & . \\
\hline SLC3A2 & $11: 62648607$ & NM_002394:c.415G>C & p.E1390 & $1.27 \times 10^{-05}$ & 25.9 & $\mathrm{~T}$ & $\mathrm{D}$ \\
\hline SLC22A24 & $11: 62849139$ & NM_001136506:c.1286-1G>A (splice site) & & 0 & 22.9 & . & . \\
\hline USPL1 & 13:31232910 & NM_005800:c.2696A>G & p.E899G & 0 & 23.6 & $\mathrm{D}$ & B \\
\hline FARP1 & 13:99083345 & NM_005766:c.1954G>A & p.E652K & 0 & 29.2 & $\mathrm{D}$ & $\mathrm{P}$ \\
\hline MLYCD & $16: 83932751$ & NM_012213:c.2T>C & p.M1T & 0 & 23.3 & $\mathrm{D}$ & B \\
\hline CHMP1A & 16:89713647 & NM_001083314:c.325C>T & p.R109X & $3.46 \times 10^{-05}$ & . & . & . \\
\hline ATG4D & 19:10662583 & NM_032885:c.977G >A & p.R326H & 0 & 25 & $\mathrm{D}$ & $\mathrm{D}$ \\
\hline MYO9B & 19:17263484 & NM_004145:c.966G>T & p.K322N & 0 & 27.6 & $\mathrm{D}$ & $\mathrm{P}$ \\
\hline KMT2B & 19:36213545 & NM_014727:c.2647C>T & p.R883W & $9.01 \times 10^{-06}$ & 34 & $\mathrm{D}$ & $\mathrm{D}$ \\
\hline RASGRP4 & $19: 38903346$ & NM_170604:c.1646G>A & p.R5490 & $9.00 \times 10^{-06}$ & 25.8 & $\mathrm{~T}$ & $\mathrm{D}$ \\
\hline ACTR5 & $20: 37400367$ & NM_024855:c.1732C>G & p.R578G & 0 & 23.7 & $\mathrm{D}$ & B \\
\hline FAM65C & $20: 49214136$ & NM_080829:c.1759G>C & p.G587R & 0 & 25.5 & $\mathrm{D}$ & $\mathrm{D}$ \\
\hline ZMAT5 & $22: 30127219$ & NM_019103:c.508G>A & p.G170s & $3.53 \times 10^{-05}$ & 34 & $\mathrm{D}$ & $\mathrm{D}$ \\
\hline
\end{tabular}

Following full exome sequencing, multiple rare heterozygous variations were identified in common between the proband and her father, with her mother's exome as a reference. This table details all shared variants (heterozygous in the proband and her father, a reference in proband's mother) with a population frequency of $<0.1 \%$. The MYOC variant is in bold.

(Max freq) the maximum frequency of a variant in any population in the public gnomAD database, (0) the particular variant has not be reported in gnomAD, (CADD, SIFT, PPH) in silico predictors of the likelihood that a variant is deleterious, $(T)$ tolerated, (D) deleterious, (B) benign, (P) pathogenic.

for this missense variant (Fig. 1B). In contrast, all unaffected individuals—-the proband's mother, maternal grandmother, and paternal grandfather-did not have this variant in MYOC. These results indicate that this variant segregates with the disease phenotype in this family.

Following ACMG guidelines for interpretation, we classified the MYOC p.Glu385Lys variant as Likely Pathogenic, based on two moderate and two supporting criteria: PM2 (absent from controls in gnomAD) and PP1_Moderate (cosegregation with disease with multiple family members); and PP3 (multiple lines of computational evidence) and PP4 (specificity of MYOC causing heritable early-onset POAG with elevated IOP, as opposed to other known genetic causes, OPTN and TBK1, that cause early-onset normal tension glaucoma with IOP $\leq 21 \mathrm{mmHg}$ ) (Richards et al. 2015; Kelly et al. 2018; Sears et al. 2019; Wang et al. 2019). 
Table 3. Details of MYOC gene variant

\begin{tabular}{|c|c|c|c|c|c|c|c|c|c|}
\hline Gene & Chr & $\begin{array}{l}\text { HGVS DNA } \\
\text { (GRCh37) }\end{array}$ & HGVS cDNA & $\begin{array}{l}\text { HGVS } \\
\text { protein }\end{array}$ & $\begin{array}{l}\text { Variant } \\
\text { type }\end{array}$ & $\begin{array}{l}\text { Predicted } \\
\text { effect }\end{array}$ & dbSNP ID & Genotype & ClinVar ID \\
\hline MYOC & 1 & g.171605427C>T & $\begin{array}{c}\text { NM_000261.2 } \\
\text { c.1153G }>A\end{array}$ & p.Glu385Lys & Substitution & Deleterious & rs1033533679 & Heterozygous & SCV000897705 \\
\hline
\end{tabular}

\section{DISCUSSION}

MYOC is a three-exon gene located on Chromosome 1q23-24 that codes for myocilin. It is highly expressed in several eye structures-in particular, the trabecular meshwork (TM), which is known to play a role in regulating IOP (Ortego et al. 1997; Polansky et al. 2000; Hewitt et al. 2008; Kwon et al. 2009; Vranka et al. 2015). Myocilin contains several functional domains, including a carboxy-terminal peroxisomal targeting domain and an olfactomedin domain - a region homologous to a family of secreted glycoproteins with uncertain function (Fingert et al. 2002; Kwon et al. 2009).

Although the association of MYOC with POAG is well-established, the normal function of the myocilin protein remains unclear. In fact, the lack of a discernible ocular phenotype in mice homozygous for a targeted null Myoc mutation suggests that it may be dispensable for normal eye function (Kim et al. 2001). However, multiple studies suggest that mutations in the olfactomedin domain lead to toxic intracellular protein accumulation (Kwon et al. 2009; Sears et al. 2019; Wang et al. 2019). Mutations resulting in aberrant exposure of the peroxisomal targeting domain in the protein may reduce myocilin excretion (Jacobson et al. 2001; Shepard et al. 2007). POAG-associated MYOC variants have also been shown to decrease myocilin solubility (Zhou and Vollrath 1999). These processes, and possibly others, produce an accumulation of intracellular myocilin aggregates, which form amyloid-like fibrils, leading to endoplasmic reticulum (ER) stress (Zode et al. 2011; Orwig et al. 2012; Patterson-Orazem et al. 2019). This, in turn, leads to TM cell damage and dysfunction, resulting in impaired aqueous humor outflow and increased IOP (Alvarado et al. 1984).

Some variants in MYOC are well-described in association with autosomal dominant familial POAG in general, whereas other variants are specifically associated with early-onset POAG with elevated IOP. The majority of these variants are missense, with an apparent clustering in exon 3, in particular in the olfactomedin domain (Bruttini et al. 2003; Hewitt et al. 2008; Tomarev and Nakaya 2009). The NM_000261.2:c.1153G>A variant described here is also located in the olfactomedin domain, but has not been previously reported in association with POAG (Fig. 1C). In silico tools predict a deleterious effect of this variant, which exchanges a highly conserved, negatively charged glutamic acid for a positively charged lysine residue in the third exon of MYOC.

\section{SUMMARY}

The finding of this NM_000261.2:c.1153G > A variant provides a notable addition to our understanding of MYOC-associated POAG. Not only does it highlight the previously identified link between MYOC and POAG, but it also provides additional support for the localization of pathogenic variants to the olfactomedin domain.

Of more immediate significance, this case emphasizes the importance of encouraging and facilitating genetic testing in families with histories of eye disorders. Identification of 
the NM_000261.2:c.1153G>A variant empowers this family to make more informed decisions for future generations. In particular, the proband and her siblings would be candidates to obtain early childhood genetic testing for any future children, which, if positive, may enable earlier POAG screening and intervention. Early diagnosis of MYOC-associated POAG may become increasingly important in the future, given current efforts to develop targeted interventions, such as TM-cell replacement from mesenchymal stem cells as well as proteostasis-based therapy to address ER stress from myocilin accumulation (Huard and Lieberman 2018; Snider et al. 2018).

Identification of this variant also provides an opportunity to connect genetic findings with clinical outcomes, especially if the proband and her family are followed over time. Furthermore, the proband identifies as Hispanic, an ethnic group overrepresented among glaucoma patients compared to Caucasians (Quigley et al. 2001). Thus, this case could inform future efforts to carry out genetic testing in Hispanic glaucoma patients, potentially identifying trends in MYOC variants within this population.

\section{ADDITIONAL INFORMATION}

\section{Data Deposition and Access}

The MYOC variant described in this family was submitted to ClinVar (https://www.ncbi.nih .nlm.gov/clinvar/) and can be found under accession number SCV000897705. Raw data were not deposited to public access databases in the absence of patient consent but may be available through correspondence with the authors.

\section{Ethics Statement}

This study was approved by the Yale University Institutional Review Board. All living individuals referenced in this case report have provided written consent to participate in our research protocol and its publication of de-identified data.

\section{Acknowledgments}

We thank the Yale New Haven Hospital for supporting the Pediatric Genomics Discovery Program, the Yale Center for Genome Analysis for performing whole-exome sequencing, and the Yale DNA Diagnostics Laboratory for confirming our de novo novel variant. We also thank Sara and Jeffery Buell for their generous contributions to the Pediatric Genomics Discovery Program. We finally thank our patient and her family for their willingness to share their stories with the medical community.

Competing Interest Statement S. Lakhani is part owner of Qiyas Higher Health, a startup company unrelated to this work.

\section{Referees}

Heidi Rehm

Anonymous

Received May 13, 2019; accepted in revised form August 9, 2019.

\section{Author Contributions}

J.C. analyzed data and wrote the manuscript. W.J. analyzed sequencing data and critically reviewed the manuscript. L.J. analyzed clinical data and contributed to writing the manuscript. J.M.M. analyzed clinical data and critically reviewed the manuscript. S.S. analyzed clinical data and critically reviewed the manuscript. L.P. analyzed data and critically reviewed the manuscript. S.L. guided experimental design and data analysis and contributed to writing the manuscript.

\section{Funding}

This study was funded internally by the Yale New Haven Hospital. 


\section{REFERENCES}

Alvarado J, Murphy C, Juster R. 1984. Trabecular meshwork cellularity in primary open-angle glaucoma and nonglaucomatous normals. Ophthalmology 91: 564-579. doi:10.1016/S0161-6420(84)34248-8

Alward WL, Kwon YH, Khanna CL, Johnson AT, Hayreh SS, Zimmerman MB, Narkiewicz J, Andorf JL, Moore PA, Fingert JH, et al. 2002. Variations in the myocilin gene in patients with open-angle glaucoma. Arch Ophthalmol 120: 1189-1197. doi:10.1001/archopht.120.9.1189

Bruttini M, Longo I, Frezzotti P, Ciappetta R, Randazzo A, Orzalesi N, Fumagalli E, Caporossi A, Frezzotti R, Renieri A. 2003. Mutations in the myocilin gene in families with primary open-angle glaucoma and juvenile open-angle glaucoma. Arch Ophthalmol 121: 1034-1038. doi:10.1001/archopht.121.7.1034

Fingert JH, Stone EM, Sheffield VC, Alward WL. 2002. Myocilin glaucoma. Surv Ophthalmol 47: 547-561. doi:10.1016/S0039-6257(02)00353-3

Hewitt AW, Mackey DA, Craig JE. 2008. Myocilin allele-specific glaucoma phenotype database. Hum Mutat 29: 207-211. doi:10.1002/humu.20634

Huard DJ, Lieberman RL. 2018. Progress toward development of a proteostasis drug for myocilin-associated glaucoma. Future Med Chem 10: 1391-1393. doi:10.4155/fmc-2018-0073

Jacobson N, Andrews M, Shepard AR, Nishimura D, Searby C, Fingert JH, Hageman G, Mullins R, Davidson $\mathrm{BL}$, Kwon $\mathrm{YH}$, et al. 2001. Non-secretion of mutant proteins of the glaucoma gene myocilin in cultured trabecular meshwork cells and in aqueous humor. Hum Mol Genet 10: 117-125. doi:10.1093/hmg/10.2.117

Kapetanakis VV, Chan MP, Foster PJ, Cook DG, Owen CG, Rudnicka AR. 2016. Global variations and time trends in the prevalence of primary open angle glaucoma (POAG): a systematic review and meta-analysis. Br J Ophthalmol 100: 86-93. doi:10.1136/bjophthalmol-2015-307223

Kelly MA, Caleshu C, Morales A, Buchan J, Wolf Z, Harrison SM, Cook S, Dillon MW, Garcia J, Haverfield E, et al. 2018. Adaptation and validation of the ACMG/AMP variant classification framework for MYH7-associated inherited cardiomyopathies: recommendations by ClinGen's Inherited Cardiomyopathy Expert Panel. Genet Med 20: 351-359. doi:10.1038/gim.2017.218

Kim BS, Savinova OV, Reedy MV, Martin J, Lun Y, Gan L, Smith RS, Tomarev SI, John SW, Johnson RL. 2001. Targeted disruption of the myocilin gene (Myoc) suggests that human glaucoma-causing mutations are gain of function. Mol Cell Biol 21: 7707-7713. doi:10.1128/MCB.21.22.7707-7713.2001

Kwon YH, Fingert JH, Kuehn MH, Alward WL. 2009. Primary open-angle glaucoma. N Engl J Med 360: 11131124. doi:10.1056/NEJMra0804630

Ortego J, Escribano J, Coca-Prados M. 1997. Cloning and characterization of subtracted cDNAs from a human ciliary body library encoding TIGR, a protein involved in juvenile open angle glaucoma with homology to myosin and olfactomedin. FEBS Lett 413: 349-353. doi:10.1016/S0014-5793(97)00934-4

Orwig SD, Perry CW, Kim LY, Turnage KC, Zhang R, Vollrath D, Schmidt-Krey I, Lieberman RL. 2012. Amyloid fibril formation by the glaucoma-associated olfactomedin domain of myocilin. J Mol Biol 421: 242-255. doi:10.1016/j.jmb.2011.12.016

Patterson-Orazem AC, Hill SE, Wang Y, Dominic IM, Hall CK, Lieberman RL. 2019. Differential misfolding properties of glaucoma-associated olfactomedin domains from humans and mice. Biochemistry 58: 1718-1727. doi:10.1021/acs.biochem.8b01309

Polansky JR, Fauss DJ, Zimmerman CC. 2000. Regulation of TIGR/MYOC gene expression in human trabecular meshwork cells. Eye (Lond) 14(Pt 3B): 503-514. doi:10.1038/eye.2000.137

Quigley HA, West SK, Rodriguez J, Munoz B, Klein R, Snyder R. 2001. The prevalence of glaucoma in a population-based study of Hispanic subjects: Proyecto VER. Arch Ophthalmol 119: 1819-1826. doi:10.1001/ archopht.119.12.1819

Richards S, Aziz N, Bale S, Bick D, Das S, Gastier-Foster J, Grody WW, Hegde M, Lyon E, Spector E, et al. 2015. Standards and guidelines for the interpretation of sequence variants: a joint consensus recommendation of the American College of Medical Genetics and Genomics and the Association for Molecular Pathology. Genet Med 17: 405-423. doi:10.1038/gim.2015.30

Sears NC, Boese EA, Miller MA, Fingert JH. 2019. Mendelian genes in primary open angle glaucoma. Exp Eye Res 186: 107702. doi:10.1016/j.exer.2019.107702

Shepard AR, Jacobson N, Millar JC, Pang IH, Steely HT, Searby CC, Sheffield VC, Stone EM, Clark AF. 2007. Glaucoma-causing myocilin mutants require the Peroxisomal targeting signal-1 receptor (PTS1R) to elevate intraocular pressure. Hum Mol Genet 16: 609-617. doi:10.1093/hmg/ddm001

Snider EJ, Vannatta RT, Schildmeyer L, Stamer WD, Ethier CR. 2018. Characterizing differences between MSCs and TM cells: toward autologous stem cell therapies for the glaucomatous trabecular meshwork. J Tissue Eng Regen Med 12: 695-704. doi:10.1002/term.2488

Stone EM, Fingert JH, Alward WL, Nguyen TD, Polansky JR, Sunden SL, Nishimura D, Clark AF, Nystuen A, Nichols BE, et al. 1997. Identification of a gene that causes primary open angle glaucoma. Science 275: 668-670. doi:10.1126/science.275.5300.668 
Tham Y-C, Li X, Wong TY, Quigley HA, Aung T, Cheng C-Y. 2014. Global prevalence of glaucoma and projections of glaucoma burden through 2040: a systematic review and meta-analysis. Ophthalmology 121: 2081-2090. doi:10.1016/j.ophtha.2014.05.013

Tomarev SI, Nakaya N. 2009. Olfactomedin domain-containing proteins: possible mechanisms of action and functions in normal development and pathology. Mol Neurobiol 40: 122-138. doi:10.1007/s12035-0098076-x

Vranka JA, Kelley MJ, Acott TS, Keller KE. 2015. Extracellular matrix in the trabecular meshwork: intraocular pressure regulation and dysregulation in glaucoma. Exp Eye Res 133: 112-125. doi:10.1016/j.exer.2014 .07 .014

Wang H, Li M, Zhang Z, Xue H, Chen X, Ji Y. 2019. Physiological function of myocilin and its role in the pathogenesis of glaucoma in the trabecular meshwork (review). Int J Mol Med 43: 671-681. doi:10.3892/ijmm 2018.3992

Weinreb RN, Aung T, Medeiros FA. 2014. The pathophysiology and treatment of glaucoma: a review. JAMA 311: 1901-1911. doi:10.1001/jama.2014.3192

Weinreb RN, Leung CK, Crowston JG, Medeiros FA, Friedman DS, Wiggs JL, Martin KR. 2016. Primary openangle glaucoma. Nat Rev Dis Primers 2: 16067. doi:10.1038/nrdp.2016.67

Zhou Z, Vollrath D. 1999. A cellular assay distinguishes normal and mutant TIGR/myocilin protein. Hum Mol Genet 8: 2221-2228. doi:10.1093/hmg/8.12.2221

Zode GS, Kuehn MH, Nishimura DY, Searby CC, Mohan K, Grozdanic SD, Bugge K, Anderson MG, Clark AF, Stone EM, et al. 2011. Reduction of ER stress via a chemical chaperone prevents disease phenotypes in a mouse model of primary open angle glaucoma. J Clin Invest 121: 3542-3553. doi:10.1172/JCI58183 


\title{
COLD SPRING HARBOR Molecular Case Studies
}

\section{Identification of a novel MYOC variant in a Hispanic family with early-onset primary open-angle glaucoma with elevated intraocular pressure}

June Criscione, Weizhen Ji, Lauren Jeffries, et al.

Cold Spring Harb Mol Case Stud 2019, 5: a004374 originally published online October 25, 2019

Access the most recent version at doi: $10.1101 / \mathrm{mcs} .0004374$

\begin{abstract}
References This article cites 29 articles, 3 of which can be accessed free at: http://molecularcasestudies.cshlp.org/content/5/6/a004374.full.html\#ref-list-1

License This article is distributed under the terms of the Creative Commons Attribution-NonCommercial License, which permits reuse and redistribution, except for commercial purposes, provided that the original author and source are credited.

Email Alerting Receive free email alerts when new articles cite this article - sign up in the box at the Service top right corner of the article or click here.
\end{abstract}

